\title{
Research on the Construction of University Financial Information
}

\author{
Huijie Zhu ${ }^{1, a}$, Chunbo Wei ${ }^{1, b}$, Guotao $\mathrm{Xu}^{1, \mathrm{c}}$ and Lan Luan ${ }^{1, \mathrm{~d}}$ \\ ${ }^{1}$ Hunnan Road, Hunnan District, Shenyang City, Liaoning Province, Shenyang Jianzhu University

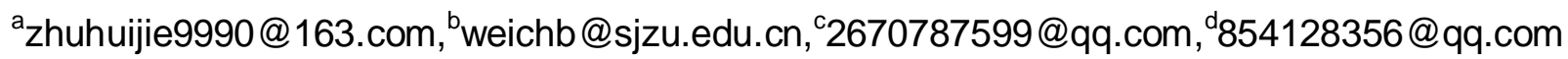

Keywords: College; Finance; Digitization; System

\begin{abstract}
Based on the characteristics of digitization system and college finance, this paper studies the construction of college finance informationization scheme based on digital system, analyzes the existing problems and countermeasures in the construction of college finance informationization, and makes use of the concept of information system construction to form a A complete set of university financial information system, the information, intelligence and financial management of colleges and universities highly integrated. Through the construction of college information technology can greatly enhance the efficiency of university financial management work, reduce the cost of work and reduce the workload of personnel, colleges and universities to provide strong support for the dual first-class construction.
\end{abstract}

\section{Research Background}

With the gradual deepening of the concept of "digital earth" and "digital city", all walks of life are beginning to push forward the "informationization" process rapidly. ${ }^{[1]}$ All colleges and universities all over the country have realized their own network within the school. With continuous improvement, the management of the campus has been gradually digitized. ${ }^{[2]}$ At the same time, the intelligent network automation system application software of campus network keeps on innovation in the accumulation and development of technology year by year. It provides the technical guarantee for the transition to the advanced management mode. Besides, the software conditions for digital campus construction and the hardware conditions are basically mature. For the gradual transition from digital campus to the construction of digital campus made a solid foundation. ${ }^{[3]}$ In addition to achieving the modernization of teaching, scientific research, management and service mode, the key to digital campus construction is the renewal of the concepts and concepts of teaching and education. It is backed up by high-performance hardware facilities and integrates the basic office, financial resources, Educational resources, logistics resources, student resources and other multi-dimensional data and information to conduct a comprehensive and unified integration, and enhance the use of information technology efficiency, and further improve the ability of information technology services in higher education and teaching work, and ultimately achieve the purpose of value-added services. ${ }^{[4],[5]}$ The construction of digital campus includes a comprehensive upgrade plan for the informationization business system in colleges and universities, including education on campus, home networking, campus information, wireless terminals, wireless coverage, card access and triple play services. At the same time, Industry management Policy information, information and other common educational resources for colleges and universities to provide a broaden their horizons and strengthen exchanges a new way. ${ }^{[6]}$

The construction of financial informationization is an important part of digital campus construction. The construction of financial informationization directly affects all kinds of educational activities of colleges and universities, and plays a very important role in all aspects of colleges and universities directly. At the same time, Almost every member of the work, study, campus life is closely related. In recent years, with the continuous expansion of the scale of major universities and the continuous expansion of their autonomy, the school-running mode has begun to shift from a traditional model centered on teaching and research to a combination of modes of research, teaching, technology application development, advisory services and production and management. Therefore, in the process of building the whole digital campus, we should give full 
attention to the construction of the financial information system and incorporate the related construction of financial information in universities into the overall planning of digital campus construction. ${ }^{[7]}$

\section{The Status Quo and Problems in the Development of University Financial Information}

In practice, dozens of colleges and universities, such as Zhejiang University, Chengdu University, Southwest University and Nanjing University of Posts and Telecommunications, are planning and implementing the construction of digital campus. Digital campus construction is no longer just on the philosophy level.

Zhejiang University informatization "second five" plan, proposed the construction of an "exciting" digital campus, this digital campus to support ubiquitous network learning, integration of innovative network technology, transparent and efficient school management, rich and colorful The campus culture, convenient and thoughtful campus life. ${ }^{[9]}$

Based on the Internet of Things, Nanjing University of Posts and Telecommunications Digital Campus builds a smart living environment integrating teaching, research, management and campus life through the use of an application service system. At the same time, through the integration and integration of application services, real-time information-free sharing can be realized. Institutional innovation and management innovation can be promoted in colleges and universities. Finally, education can be fully informatized, scientific decision-making and management standardization can be achieved.

Colleges and universities have made some achievements in financial informatization. The concept of informatization has been gradually deepening to the ideological concepts of the financial departments of colleges and universities as well as staffs of related departments, and the work efficiency has been correspondingly raised. However, with the continuous promotion and deepening of the construction of digital campus, many problems in the construction of financial information construction are highlighted. These problems hinder the development of financial informationization. Through analysis and conclusion, the problems in the construction of financial informationization are mainly reflected in the following aspects: First, the top-level design of financial informationization is absent; second, the data connectivity is poor; Third, the development of financial information personnel lags behind; Fourth, internal Control system is weak. ${ }^{[10]}$

\section{Based on the Digital System of University Financial Information Construction}

\section{College Financial Business Information Processing}

The informationization of business processing is the basis for the full realization of financial information construction, and the prerequisite for the implementation of such goals as networking, informationization, budget control and control precision, funding guarantee visualization and intelligent decision-making support. Only by standardization and informatization of business processing can we further realize the interaction, sharing and comprehensive utilization of financial data and information, resources.

\section{Financial Accounting Automation}

Make full use of "Internet $+"$ in the field of university finance. The financial information system upgrade, while extending the traditional advantages of seamless integration with other financial software to ensure data consistency and maximize management efficiency. In the digital campus background software accounting information accounting automation can be realized, such as basic accounting data once entered, other related documents automatically generated, the full realization of online reimbursement, the financial lobby will no longer be waiting long queues captain this low Efficient office mode, the financial staff only need to review the rationality of the original documents online, greatly improving the efficiency and quality of financial services.

\section{Budget Management Refined}

Based on the digital campus construction cloud computing technology to build the financial cloud platform, combined with powerful data analysis and processing capabilities, can reduce the 
intermediate level of budget management, to achieve more accurate budget management; the same time, to enrich the budget management model to improve the efficiency of budget management . With strong computer data processing and rapid network transmission capabilities, financial information construction should achieve real-time monitoring budget and precision as the goal.

\section{Intelligent Decision Analysis}

Intelligent decision analysis includes funding support visualization and decision support intelligence. Funding protection Intelligent digital key technology through digital campus big data analysis will be scattered financial expenditure data summary, integrated analysis to automatically output indicators, trends graphics, tables and other visual forms of intuitive, timely and proactive to faculty and management decision-making layer To show, in order to facilitate financial analysis, discover the law, supporting decision-making. Visualization of funding support is conducive to strengthening financial control, strict budget implementation, improve work efficiency to make management more intelligent. Intelligent financial support decision-making refers to the financial information in the process of continuous improvement to increase the auxiliary decision-making intelligent system module, the development of financial analysis of intelligent analysis system. Form a unified decision-making analysis platform for multi-sectoral and multi-system linkage, facilitate leaders of schools to understand the financial status of colleges and universities whenever and wherever possible, and provide strong support for the precise decision-making of financial department leaders and school leaders.

In the financial information construction of colleges and universities, we should regard accounting and financial management as two major modules as the construction center of gravity, combined with the existing information system in colleges and universities to reorganize the financial information business processes should be planned as follows:

Three core business information: budget, accounting, data analysis: the budget covers all expenditures of the university that year, so the budget business to be at the center. Accounting mainly includes the wage system, general economic business accounting, as well as student accounting fees. Data analysis is the use of a variety of statistical methods to analyze the collected financial information data to extract valid information to form a conclusion, which is based on the purpose of providing improvement and decision-making basis.

To achieve multi-functional application platform. In order to comply with the development needs of digital campus construction and further bring convenience to teachers and students, the construction of financial informationization should be further perfected to achieve the full range of service platform requirements. Such as salary inquiry, bill inquiry, online booking, reimbursement progress inquiry, foreign information disclosure, student self-help system and other application system information.

To complete the financial informationization and docking with other departments in the school

Finance-related departments are Technology Department, Personnel Office, Asset Management Office, Academic Affairs Office, Graduate School, Student Affairs Office and so on. There are also "islands of information" in various application systems between departments. It is necessary to build an integrated business application and a decision-making business application platform with strategic support functions so as to eliminate obstacles among various departments and improve internal teaching and research capabilities as soon as possible Financial accounting software information.

Financial Accounting Software Informationization: The financial accounting software should be systematized specifically including the budget management system, online reimbursement system, bank direct connection system, financial information and data exchange platform, decision support system.

\section{Financial Information Construction Security Measures}

\section{Change the Concept of Leadership in Colleges and Universities}

University leaders and relevant departments attach great importance to the construction of financial information in order to ensure the provision of a solid backing. Second is to step up efforts to 
promote information technology so that all relevant departments of personnel can have a real understanding of financial information and understanding of the funding to be fully supported to ensure the smooth progress of college financial information construction.

\section{Establishment of Information Construction Agencies}

The smooth progress of financial information construction under the background of digital campus is a multi-dimensional and multi-dimensional systematic project,

Need the coordination of the relevant functional departments to participate, not the Treasury alone to complete, we must mobilize the ministries

The door actively and responsibly involved, brainstorming, each responsible. Therefore, colleges and universities want to actually implement the construction of financial informationization, it is necessary to rely on existing organizations, set up under the digital campus construction team specialized financial information construction leading group.

\section{Develop a Sound Workflow}

Relevant management departments should conduct in-depth study of the problems existing in the process of financial informationization in colleges and universities as well as the demand for relevant policies, and promulgate the relevant systems for the construction of financial information as soon as possible, so as to make clear the responsibilities of university administrators and the general planning of financial informationization A certain degree of restraint and guidance to promote the university management's emphasis on the construction of financial information as well as the normative management of information technology.

\section{Do the Top Financial Design}

In the early stage of financial information construction in colleges and universities, we should attach great importance to the top-level design, in-depth user, fully understand the system construction needs, and system service objects related to a series of processes are clear, understand, and the service sector leadership and work Personnel conduct many forums and exchanges, after many studies, and ultimately determine the development needs. Subsequently, according to the results obtained from the survey, we adhered to a scientific and rigorous working attitude, combined theoretical knowledge with concrete practice, formulated a plan and defined our objectives, and focused our efforts on the difficulties and priorities of the project. Therefore, in the top-level design and overall planning truly reflects the unity of leadership, decision-making is reasonable, responsible for grading, clear management.

\section{Summary}

This article aims at the status quo and existing problems of the construction of the financial informationization in the domestic colleges and universities to construct a complete financial informationization construction system, and put forward the matching guarantee measures. This paper analyzes the background and current situation of the development of financial informationization in colleges and universities, and analyzes the existing problems. It puts forward the construction goal and train of thought for the construction of informationization in colleges and universities, realizes the high integration between the university finance and the digital system and constructs a set of reasonable financial Xuanhua heart of the building system. Hoping to help finance the construction of colleges and universities.

\section{References}

[1] Yujuan X. A Study on the Application of ERP Financial Management System in Logistics Enterprises Based on Agile Financial Chain Model[J]. 2013.

[2] Jeremy Rifkin, The Internet of Things ,the Collaborative Commons, and the Eclipse of Capitalism [M], Advanced Research ;2014

[3] Wei Xing, Mei Xian, Yun You Tu. Research on the Internal Control and Reorganization of Enterprise Accounting Process under the Information Environment[J]. Applied Mechanics and Materials .2014 (687) 
[4] $\mathrm{Xi}$ Wang.Research on the Improvement of Internal Control under Accounting Informationization Environment[J]. Applied Mechanics and Materials.2014 (687)

[5] Hollis, Ashbaugh-Skaife,Daniel, Collins William R.Kinneyetal."The Effect of SOX Internal Control Deficiencies and Their Remediation on Accrual Quality"[M]. The Accounting Review. Vol.83. No.1. 2008,P217-250

[6] Ringa Raudla, Erkki Karo,Kaija Valdmaa, Rainer Kattel. Implications of project-based funding of research on budgeting and financial management in public universities, Higher Education, December 2015, Volume 70, Issue 6.

[7] T.L.Huong Nguyen.Building human resources management capacity for university research: The case at four leading Vietnamese universities. Higher Education, February 2016, Volume 71, Issue 2.

[8] Peter Galbraith. Out of the Frying Pan: Into the Fire of Post-Global Financial Crisis (GFC) University Management. Higher Education Policy, December 2013, Volume 26, Issue 4.

[9] R.Scott, Tillesen. The Graduate School of Credit and Financial Management Icing On The Cake. Business Credit,2005,107 (6).

[10]Xi Wang. Research on the Improvement of Internal Control under Accounting Informationization Environment[J]. Applied Mechanics and Materials.2014 (687) 